\title{
CONSTITUTIONAL DIFFERENCES BETWEEN MUAY THAI FIGHTERS FROM THAILAND AND FROM GERMANY
}

\author{
Christoph Krick, Christoph RaschKa \\ Institute of Sports Science, Julius Maximilian University of Würzburg, Germany
}

\begin{abstract}
The aim of the following study is to present the body composition of male Muay Thai fighters that were measured in Thailand and in Germany. As a control group, German college students were also measured.

The three groups were separated into five different groups: experienced and inexperienced. Muay Thai fighters from Thailand were not separated since they were much more experienced, more advanced, than their German counterparts.

Experienced and inexperienced were defined by the amount of training that each fighter conducted every week: Training of less than three times a week was considered as "inexperienced".

The measurements in this study were performed under a standardized method by the author. The measured results were analyzed by using Microsoft Excel 2010 and IBM SPSS 16.

The results of the present study showed that the Muay Thai fighters from Thailand were significantly smaller than the German Muay Thai fighters and the college students.

This study also used the methods developed by Parnell, Heath and Carter, Knussmann and Conrad. The body mass index was also used in the study.
\end{abstract}

Keywords: Muay Thai; martial art; Thailand; Germany; somatotype; body composition; sports anthropology 


\section{INTRODUCTION}

Muay Thai, a sport art more than 2,000 years old, has become a very popular form of martial arts these days. While popular all over the globe, the majority of the best Muay Thai fighters can be found in Thailand.

That is the reason why the author of this study went to Thailand to gather data and to compare the Thai and German data. An empirical study was conducted where more than fifty body regions were measured. Measurements included height, width, depth, weight, and fat measurements. These data were then transferred into different models in order to be able to produce a unique somatochart (according to Heath and Carter) or a matrix (according to Conrad)

\section{THE PARTICIPANTS IN THE STUDY}

This study included 119 participants. The minimum age requirement for the participants was the age of 16 years, and all the participants were males.

40 participants were German Muay Thai fighters whom the author measured in Germany.

39 participants were from Thailand, and 40 students from Frankfurt University (sport students) were recruited as a control group for this study.

The 40 German Muay Thai fighters and the 40 sport students were separated into two different groups, experienced and inexperienced. The definition for these categories was based on the weekly training sessions conducted.

Those who trained less than three times a week were considered inexperienced, while those who trained more than three times a week were regarded as experienced. Therefore, the Muay Thai fighters from Thailand could only be considered experienced since they trained almost daily. 


\section{Parnell}

With Parnell's methodology, the constitutional differences between the participants can be seen: while the experienced German Muay Thai fighters were located between endomorphy and mesomorphy, the experienced Muay Thai fighters from Thailand showed a clear trend towards mesomorphy as seen in Figures 1 and 2.

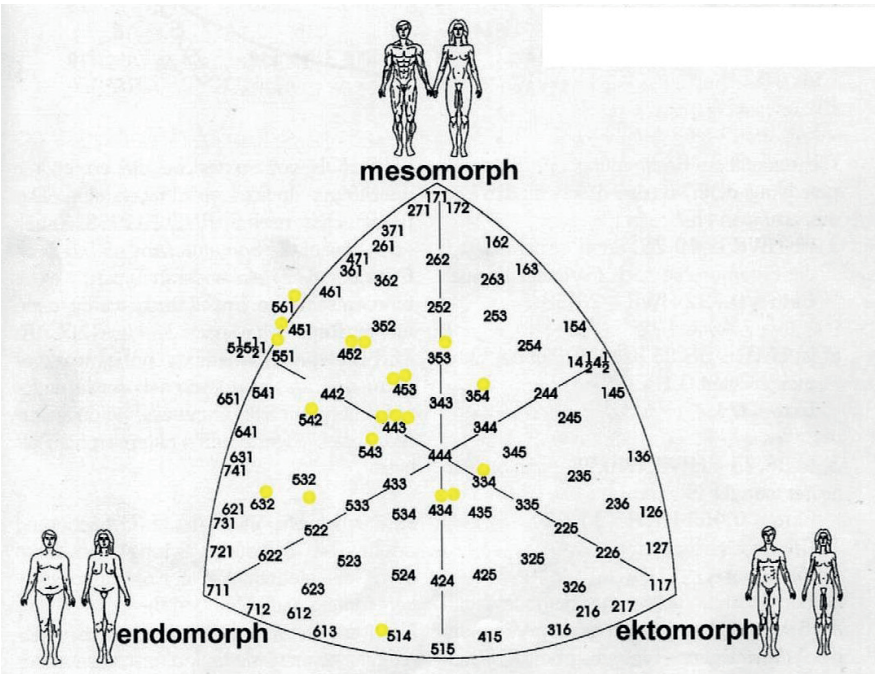

Figure 1. Somatochart according to Parnell's method. The yellow dots represent the experienced German Muay Thai fighters.

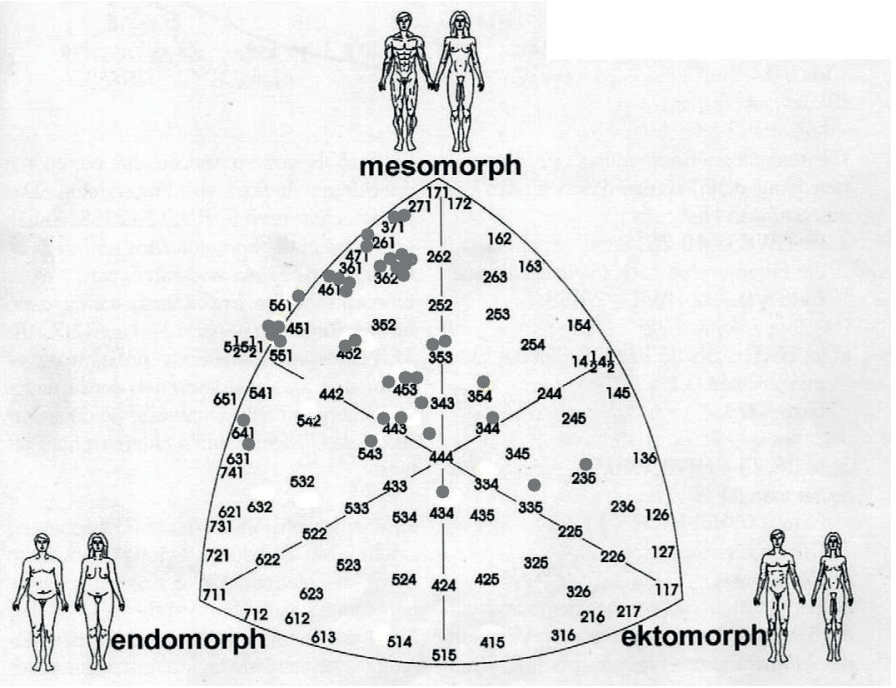

Figure 2. Somatochart according to Parnell's method. The grey dots represent the Muay Thai fighters from Thailand. 


\section{Conrad}

The results in the Conrad matrix showed that the experienced German Muay Thai fighters had a much higher tendency towards the hyperplastic region whereas the Muay Thai fighters from Thailand were more distributed between the hyperplastic and hypoplastic regions. On the leptomorphic-pycnomorphic axis, the Muay Thai fighters from Thailand showed a tendency towards the leptomorphic region. The German Muay Thai fighters, on the other hand, tended towards the pycnomorphic region.

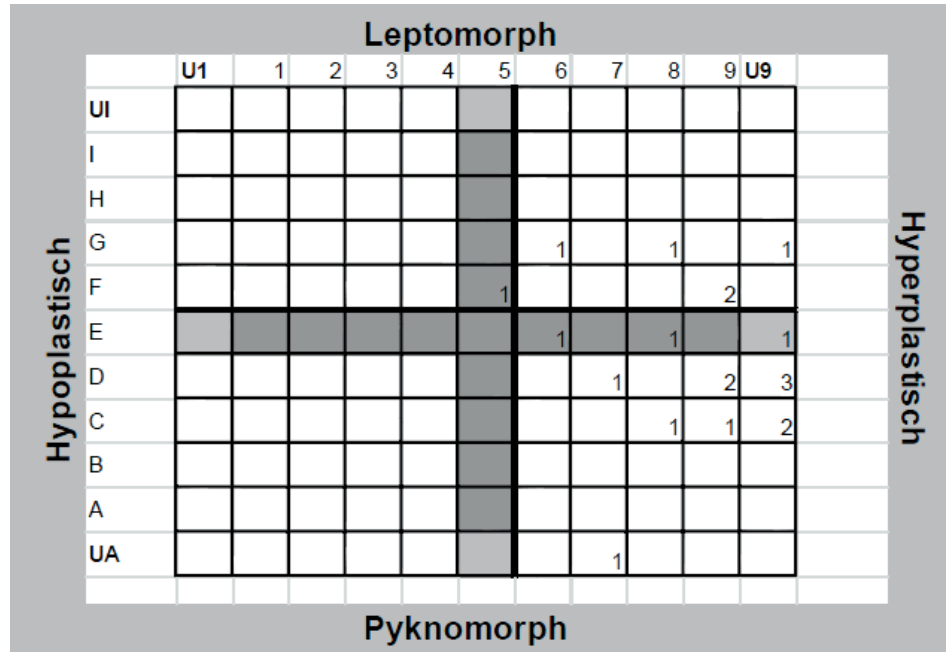

Figure 3.

Matrix according to Conrad's method. The numbers in the matrix represent the German Muay Thai fighters. The numbers in the Matrix show the quantity of participants.

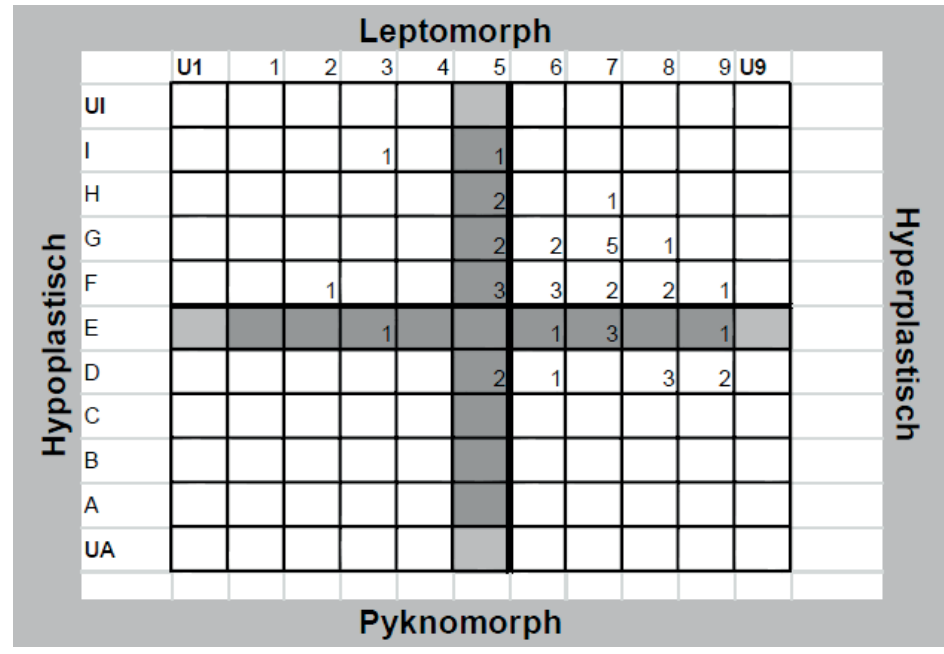

Figure 4.

Matrix according to Conrad's method. The numbers in the Matrix represent the experienced Muay Thai fighers from Thailand while the numbers in the matrix show the quantity of participants. 


\section{Tittel and Wutscherk}

The AKS-index by Tittel and Wutscherk represents the lean body substance of the participants in this study. The experienced German Muay Thai fighers where the ones with the highest AKS-index Score of 1.2.

Table 1. AKS-index according to Tittel and Wutscherk.

\begin{tabular}{llcc}
\hline Participants & Experienced & Mean & Standard deviation \\
\hline German Muay Thai fighters & Inexperienced & 1.1 & 0.1 \\
\cline { 2 - 4 } & Experienced & 1.2 & 0.1 \\
\cline { 2 - 4 } & Total & 1.1 & 0.1 \\
\hline Muay Thai fighters from Thailand & Experienced & 1.1 & 0.1 \\
\cline { 2 - 4 } & Total & 1.1 & 0.1 \\
\hline Sport students & Experienced & 1.1 & 0.1 \\
\cline { 2 - 4 } & Inexperienced & 1.0 & 0.1 \\
\cline { 2 - 4 } & Total & 1.0 & 0.1 \\
\hline
\end{tabular}

\section{DISCUSSION}

It was possible to document in this study that there were significant differences between various groups. Not only could it be shown that there were significant dissimilarities between the different schools of constitution, but also between the particular measurement points that were measured.

It could be shown that:

- there were highly significant differences in height measurements (i.e. body height) between the experienced sport students $(184.2 \mathrm{~cm}+/-4.6 \mathrm{~cm})$ and the experienced Thais $(168.1 \mathrm{~cm}+/-7.5 \mathrm{~cm})$,

- there were highly significant girth differences (e.g. head girth $57.5+/-1.4 \mathrm{~cm}$ in the German Muay Thai-fighters versus $55.8+/-1.7 \mathrm{~cm}$ in the Thais),

- there were also highly significant differences between the groups in width measurements (e.g. cheekbone width $12 \mathrm{~cm}+/-0.9 \mathrm{~cm}$ in the German Muay Thai fighters versus $12.4 \mathrm{~cm}+/-0.6 \mathrm{~cm}$ cheekbone in the Thais,

- the measurements of skinfold fat did not show highly significant differences between the groups.

In the present study it was possible to demonstrate the differences between the participants from Germany and Thailand. It is certainly interesting to see that, in a discipline that is trained on a daily basis, body composition can vary significantly. 


\section{REFERENCES}

1. Bernhard W., Jung K. (1998). Sportanthropologie. Fragestellungen, Methoden und Ergebnisse am Beispiel der Laufdisziplinen und des alpinen Skirennsportes. Stuttgart: Gustav Fischer.

2. Bös K., Hänsel F., Schott N. (2004). Empirische Untersuchungen in der Sportwissenschaft. Hamburg: Czwalina.

3. Carter J. (Volume 80 1984). Somatotypes of Olympic Athletes from 1948-1976. Medicine and Sports Science, 80-109.

4. Carter J., Parizkova J. (1978). Changes in Somatotype of European Males between 17 and 24 Years. American Journal of Physical Anthropology, 48, 251-254.

5. Conrad K. (1941). Die Konstitutionstypen als genetisches Problem. Berlin.

6. Conrad K. (1963). Der Konstitutionstypus. Berlin, Göttingen, Heidelberg: Springer Verlag.

7. Heath B. H., Carter J. (1966). A Comparison of Somatotype Methods. American Journal of Physical Anthropology, 24, 87-100.

8. Heath B. H., Carter J. (1966). A Comparison of Somatotype Methods. American Journal of Physical Anthropology, 24, 87-99.

9. Knußmann R. (1965). Konstitution und Geschlecht. Anthrop. Anz. 29, 146-151.

10. Knußmann R. (1980). Vergleichende Biologie des Menschen (1 Ausg.). Stuttgart: Gustav Fischer.

11. Knußmann R. (1996). Vergleichende Biologie des Menschen (2 Ausg.). Stuttgart: Gustav Fischer.

12. Parnell R. (1954). Behaviour and Physique. London: Arnold.

13. Parnell R. (1954). Somatotyping by physical anthropometry. Am. J. Phys. Anthop, 12, 209-215.

14. Raschka C. (2006). Sportanthropologie. Köln: Sportverlag Strauß.

15. Tittel K., Wutscherk H. (1972). Sportanthropometrie: Aufgaben, Bedeutung, Methodik und Ergebnisse biotypologischer Erhebungen. Barth.

\section{Address for correspondence:}

Prof. Dr.med. Dr.rer.nat. Dr.Sportwiss. Christoph Raschka

Institute of Sports Sciences, Julius-Maximilians-University, Germany

Judenbühlweg 11

D-97082 Würzburg

E-Mail: christoph.raschka@uni-wuerzburg.de 